\title{
Gonad Development in the Female Nigerian Clarias Gariepinus Burchell 1822
}

\author{
Babatunde Akeem Saka* and Olanike kudirat Adeyemo \\ University of Ibadan, Nigeria ibadan, Nigeria
}

\begin{abstract}
Some studies have established some physiological parameters for the African sharp tooth catfish Clarias gariepinus in some regions in the world which have been found to vary considerably from what is observed in the Nigerian species. This study indicates that $C$. gariepinus matured five months after hatching in the female at approximately $700 \mathrm{~g}$. This however differs from a previous study of wild $C$. gariepinus which reported that the age of first maturity is 1 year, when the body weights of the fishes are approximately $108 \mathrm{~g}$ for females.
\end{abstract}

\section{Keywords: Biology; Catfish; Breeding fish; Veterinary medicine}

\section{Introduction}

The African sharp-tooth catfish, C. gariepinus, as presently recognized, originates from Southern Natal and the Orange River in the south, northwards through central, west and northern Africa, through the Middle East and into Eastern Europe. It is said to be the freshwater fish species with the widest latitudinal range in the world. The African sharp-tooth catfish is eurytopic and inhabits a very wide range of inland waters, including streams, rivers, swamps, under-ground sinkholes as well as in shallow and deep lakes. They thrive in shallow turbid lakes, as well as in deep clear lakes, but are particularly successful in rivers [1]. Several studies have established some physiological parameters for the African sharp-tooth catfish C. gariepinus in some regions of the world which have been found to vary considerably from what is observed in the Nigerian species. It has been reported that Turkish C. gariepinus attains sexual maturity a year after hatching under standard laboratory conditions with initial detection of eggs at 9 months of age and at 123 grams for the female [2]. The same result was reported for maturity at 113 grams for the female in the wild (ASI River) [3]. Furthermore, [4] stated that maturity is related to age alone in C. gariepinus while [5] maintained that maturity is related to size rather than age though the age has a contribution. Presently, limited histological description for ovary and oocytes development exists for Nigerian Clarias gariepinus which could be used in gonadal histological assessment. Most histological studies include control groups to serve as reference of normal histology. However, in previous gonadal histo-toxicity studies it has being established that control groups exhibit a range of histological characteristics not confirmed to be normal. More uncertain was the control specimen's history prior to the use in the experiment, which could have resulted in the presence of histological alterations. Apart from toxicant-induced lesions, histological characteristics are also known to vary among species, age, season, sex, spawning period, nutritional condition etc [6]. Breeding fish under controlled conditions allow these factors to be known and to be documented at the time of tissue sampling. An accurate histological assessment therefore requires knowledge and understanding of the normal histological structure of the organ and species in question. Baseline reproductive biology of fish is increasingly being studied to support interpretation of tests with potential endocrine disruptor chemicals [7]. Therefore, examination of normal oocyte and ovary histology of the Nigerian C. gariepinus is imperative to serve as reference that can be used to compare suspected pathological conditions or otherwise [8]. State that identification of tissue lesions requires a baseline appreciation of normal tissue conditions. In the meantime, field reports have a successful utilization of Nigerian
C. gariepinus of 5 months for spawning which is not in tandem with reports on the Turkish species. In this study, the reproductive cycle of Nigerian C. gariepinus was examined under standard laboratory conditions. The methods used included an identification of oocytes at different stages of development, group categorization and a histological and morphological study of the female gonads.

\section{Materials and Methods}

\section{Experimental fish and system}

African Sharp-tooth catfish larvae were obtained through the artificial reproduction method described by [9] and [10] Female brood stock fish were selected from the local fish supplier on the basis of their swollen abdomens which was then depressed at the time of purchase to express some of the content out through the papillae in order to ensure reproductive viability, they were then taken alive to the aquaria unit of the Department of Public Health and Preventive Medicine, Faculty of Veterinary Medicine University of Ibadan. Male broods which were selected on the basis of their size, age and papillae development were also transported to the same aquaria unit. The fishes were held for about seven days in the aquaria unit to allow them overcome the stress of transportation and acclimatize. Reproduction was done by first injecting Ovuprim (a synthetic hormone) into the female to induce oocyte maturation and ovulation. Subsequently the injected female was kept in a dry 1000L plastic tank. After 10-12 hours, the female was stripped of the eggs manually with hands into a clean and dry aquarium where the fertilisation was done. Male broods were then sacrificed, opened vertically, the testes removed and the milt squeezed from it onto the stripped eggs. The mixture was gently mixed with a plastic spoon and the excess milt was washed away with normal saline. This method of fertilisation is referred to as the DRY method. The eggs hatched within 1 or 2 days at $26 \pm 1^{\circ} \mathrm{C}$. As soon as the eggs begin to hatch, dead eggs and other dirt were removed by carefully siphoning

*Corresponding author: Babatunde Akeem Saka, University of Ibadan, Nigeria, Tel: 2348030791028; E-mail: sakababatunde@gmail.com

Received December 15, 2014; Accepted March 27, 2015; Published April 30 2015

Citation: Saka BA, Adeyemo OK (2015) Gonad Development in the Female Nigerian Clarias Gariepinus Burchell 1822. J Aquac Res Development 6: 341. doi: 10.4172/2155-9546.1000341

Copyright: @ 2015 Saka BA, et al. This is an open-access article distributed under the terms of the Creative Commons Attribution License, which permits unrestricted use, distribution, and reproduction in any medium, provided the original author and source are credited. 
these out with a tiny mouth hose. After hatching, the larvae were left in the happa (this is a rectangularly constructed net with extremely tiny holes and the top open which is suspended on stakes while inserted in a large body of water to permit frequent change in water for the larvae without losing the larvae) and a flow through system was established in the first week after hatching. The aquarium system was housed inside an experimental room with a natural photoperiod ( $12 \mathrm{~h}$ light and 12 $\mathrm{h}$ dark). During the experiment the larvae were first fed pre-formed Artemia. After 20 days they were fed powdered trout feed (Coppens). Juveniles were fed pelletized trout floating feed (Coppens), with the adoption of a static water system in which case $80-90 \%$ of the water in the tank was changed daily before the morning feed. Adults received the same feed but of bigger pellet size $(4.5-6 \mathrm{~mm})$. From the age 1 month up to 5 months, 4-5 fish from each pond were sampled. In sampling, each fish was weighed and recorded, total and focal lengths taken and recorded as well. They were then sacrificed and their sexes were recorded. Finally the gonads were harvested, weighed and preserved in Boiun's fluid.

\section{Histological procedures}

Gonad development was determined histologically by light microscopy. The developmental stages of the ovaries were determined for each fish. Oocytes were classified by developmental stage adapted from [11]. Gonad samples were fixed for $24-48 \mathrm{H}$ in Bouins solution and then subjected to histological processing as described by [12]. All slides were subjected to histological assessment using compound light microscopy. The developmental stages of the gonads were determined by identifying histological features. Subsequently, the sexual maturity/ stage of the sample groups was confirmed.

\section{Results}

At age few hours to 8 weeks of age, a gross dissection of the fish samples revealed the absence of the gonads. The female gonads became active and differentiated as from the male as from the third month.

\section{Morphology}

\section{Ovary}

Stage 1 ovary: At three months of age, the ovaries were seen attached to the dorsal-lateral lining of the peritoneal cavity. Growing like a tube, hollow as a thin ribbon-like structure, creamy-white and translucent. The edges are smooth and the ovary looks so much like the testes. It is quite difficult to differentiate between the ovary and the testes at this stage. This Stage is referred to as Stage 1 ovary. A large number of sampled fishes of this age presented this stage of ovary.

Stage 2 ovary: Stage 2 ovaries had smooth edges, ovaries were reddish-brown and granular in appearance. At the end of stage 2, the ovaries are completely filled up with clearly visible oocytes of different sizes which will be whitish. This is the maturing stage.

Stage 3: Stage 3 ovaries occupy a significant part of the abdominal cavity. The ovaries are big and present visible greenish oocytes in the African catfish and a well-developed vascularization. The ovaries will be matt-green at the onset of this stage and clear green at the peak of this stage. However, the oocytes are still included in the ovarian lamellae, and the ovary lumen was empty. These ovaries characterize fully vitellogenic females, close to the spawning period. This stage occurred at the fourth month of age and it is referred to as an advanced maturation stage.

Stage 4: Stage 4 ovaries presented clear green ovaries which are transparent showing the greenish oocytes. This aspect is almost identical to stage 3 ovaries, but the oocytes are partially ovulated (free in the ovarian cavity $=$ ovules) and can be expelled with a gentle pressure on the fish flanks. The ovary reaches its maximal development. This is an ephemeral stage just before the actual spawning event. Ovaries at this stage are said to be ripe. This stage occurred at about 5 months (Figure 1). At four months, ovaries were seen to contain oocytes at both the Secondary Growth Phase SGP as well as the maturation stages. Oocytes at the SGP are further divided into two stages referred to as the vesicle formation stage (St 3 ) and the exogenous yolk formation stage (St 4). Cortical vesicles were detected for the first time. These were usually spherical structures that appeared at random at various depths in the ooplasm. They provided the first evidence for initiation of the secondary growth phase and appeared usually as empty unstained vacuoles (Figure 2). Stage 4 oocytes have an enlarged nucleus which begins to get irregular and vacuolization may be seen in two rows. The nucleus consisted of many nucleoli and continued to enlarge, becoming very irregular in shape. The Zona Radiata was more conspicuous. The process of vacuolization was completed by the formation of 2 rows of vacuoles.

Stage 5: Oocytes can be identified by the presence of projections into the cytoplasm from the nucleus. However this was difficult to identify as it required much magnification. The nucleus is very small and the nucleolus can rarely be identified. The zona radiata however becomes thicker and more conspicuous. Stage 5 oocyte is the biggest in diameter of all the oocytes (Figure 3).

\section{Discussion}

Nigerian C. gariepinus matured at five months after hatching in the present study. This agrees with those by [13] and [4]. However it differs from a previous study of wild C. gariepinus which reported that the age of first maturity is 1 year, when the body weights of the fishes are approximately $108 \mathrm{~g}$ [3]. Early maturation in fish has been achieved either by genetic selection or better nutrition, revealing a correlation between maturation and growth [14]. Full maturation of $C$. gariepinus was found to be 6 months of age in this study [4]. stated that maturity is related to age in C. gariepinus; however, our observations showed that maturity was related to size rather than age. Although age cannot be totally excluded in the determination of puberty the age of puberty appears to decrease with size. On the basis of our observations in this
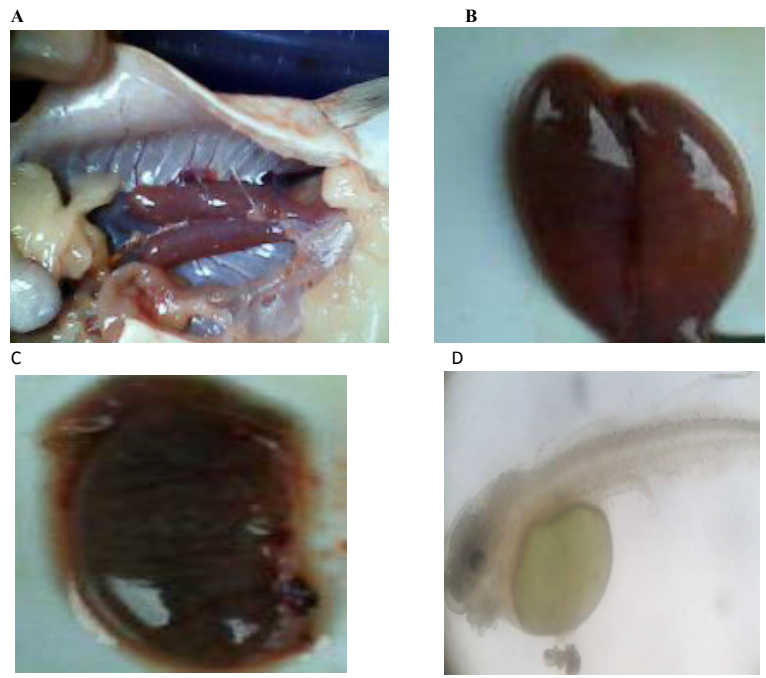

D

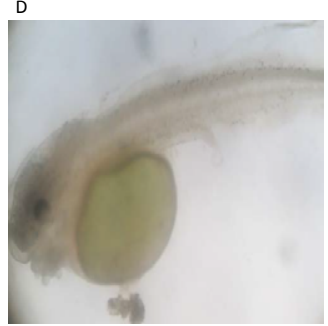

Figure 1: A- shows a stage 2 ovary (O). B-shows a stage 3 ovary.C-shows stage 4 ovary.D-shows a hatchling after a few hours. Mag x40. 

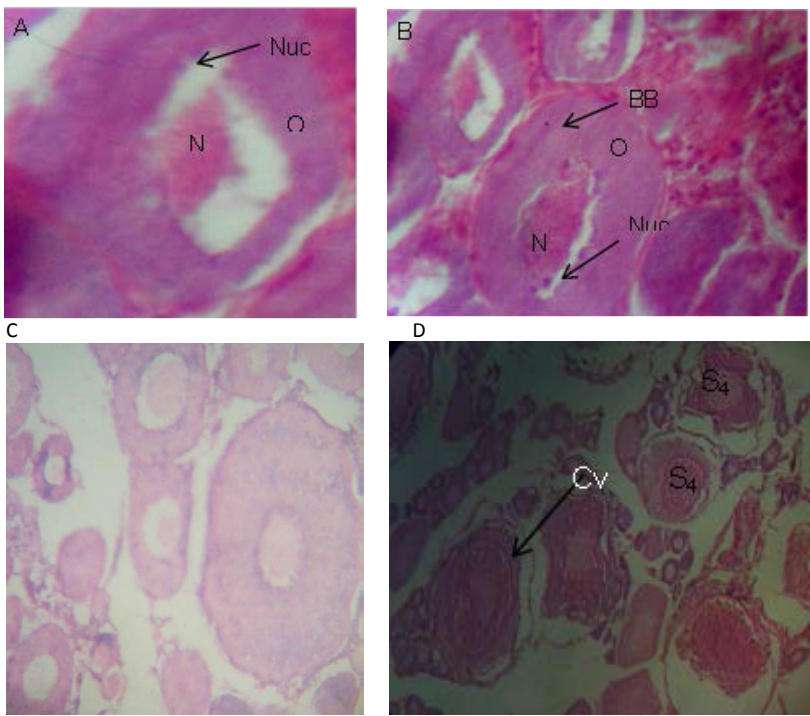

Figure 2: A- Oocyte at the chromatin stage showing nucleus $(N)$, nucleolus (Nuc) and ooplasm (O). B- Perinucleolar stage 2 showing balbiani body (BB). C- Stage 3 oocyte. D- stage 4 oocyte with cortical vesicle (CV). Mag x40.

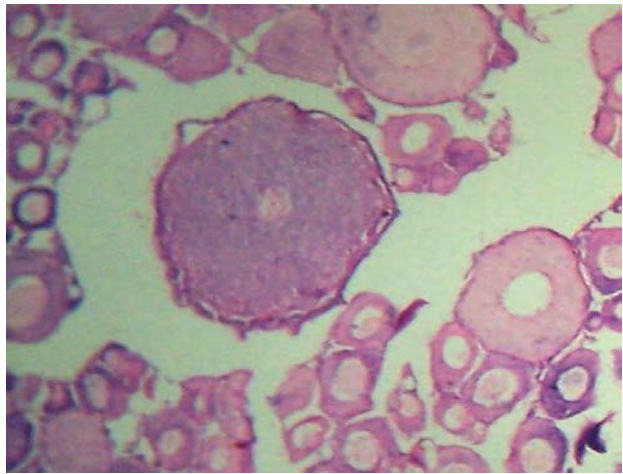

Figure 3: Stage 5 oocyte.

study, we propose that puberty depends more on size than age, since in the same aquarium (all fish were the same age) the larger ones matured earlier than the smaller ones. In the classification of the different stages of the ovary development, owing to the different appearances it can take, ovarian stage 2 is sometimes divided into two or more distinct stages in the literature on a specific species [15-20]. However, as it represents a single continuous physiological state (initiation and development of the vitellogenesis) and as its aspect may vary a great deal depending on species, it appears simpler and more logical to keep it as a single stage in this synthetic scale. The histological characteristics of oocyte development in C. gariepinus described in this study are divided into 3 phases: Primary Growth Phase, Secondary Growth Phase, and maturation. The maturation phase included hydration and stage 6 oocytes. As in other teleosts, oogonia of C. gariepinus proliferated and turned into primary oocytes, which subsequently grew within follicles, formed cortical alveoli, entered vitellogenesis, underwent maturation, and finally ovulated. The changes that occurred during these phases were similar to those reported for catfish and some other teleosts [2124]. Examined ovaries showed oocytes in various stages and different sizes. At the maturation stage, the major part of the ovary was occupied by stage 6 oocytes in the sixth month, which comprised a synchronous population of larger oocytes, defined as a clutch. Yet, a large number of previtellogenic and vitellogenic oocytes were also detected among the mature oocytes, which comprised a more heterogeneous population than the population from which the clutch were recruited. On the basis of this description, C. gariepinus might be classified as having a group-synchronous type ovary development. In conclusion, this study has shown that the Nigerian specie of African sharp tooth catfish $C$. gariepinus matured 6 months after hatching which is earlier than the Turkish specie thus indicating a specie variation. Ovarian development was the group-synchronous type. It is as well worthy of note that the Nigerian specie of C.gariepinus grows bigger and faster than the Turkish specie. At their puberty ( 5 months) the average weight for the male was $700 \mathrm{~g}$ and the female was $900 \mathrm{~g}$. These results suggest that 5 months old C. gariepinus can be used as brood stock for seed production in captivity.

\section{References}

1. Bruton MN (1979) The breeding biology and early development of Clarias gariepinus (pisces, clariidae) in Lake Sibaya, South Africa, with a review of breeding species of the subgenus Clarias (clarias). Trans Zool Soc London 35:1-45.

2. Cek S, Yilmaz E (2007) Gonad development and sex ratio of Sharptooth catfish (Clarias gariepinus Burchell, 1822) cultured under laboratory conditions. Turk J Zool 31: 35-46.

3. Yalçın S, Solak K, Akyurt I (2001) certain reproductive characteristics of the African Catfish (Clarias gariepinus Burchell, 1822) living in the River Asi Turkey. Turk J Zool 25: 453-460.

4. Schulz RW, Corput VL, Dommerholt JJ, Goos HJTh (1994) Sexual steroids during puberty in male African catfish (Clarias gariepinus): serum levels and gonadotropin- stimulated testicular secretion in vitro. J Com Physiol B 164: 195-205.

5. Çek S, Erdal Y (2007) Gonad Development and Sex Ratio of Sharptooth Catfish (Clarias gariepinus Burchell, 1822) Cultured under Laboratory Conditions. Turk J Zool 31: 35-46

6. Takashima F, Hibiya T (1995) An atlas of fish histology.

7. Jensen KM, Korte JJ, Kahl MD, Pasha MS, Ankley GT (2001) Aspects of basic reproductive biology and endocrinology in the fathead minnow (Pimephales promelas). Comp Biochem Phys Comp Biochem Physiol C 128: 127-141.

8. Yonkos LT, Kane AS, Reimschuessel R (2000) Fathead minnow histology atlas: Worldwide web outreach and utilization. Mar Environ Res 5: 312.

9. Hogendoorn H, Vismans MM (1980) Controlled propagation of the African catfish; Clarias lazera (C\&V) artificial reproduction. Aquaculture 21:39-53.

10. Woynarovich $E$, Horvath $L(1980)$ The artificial propagation of warm water fin fishes: A manual for extension. FAO Fish Tech Pap 201:183.

11. Bromage NR, Cumaranatunga PRT (1987) Oocytes development in the rainbow trout with special reference to vitellogenesis and atresi. Proceedings of the $3^{\text {rd }}$ International Symposium on the Reproductive Physiology of Fish In: D.R. Idler, L.W. Crim, and J.M. Walsh.(eds.). St John's, Newfoundland Canada, p. 194

12. Cavaco JEB, Vischer HF, Lambert JGD, Goos HJTh, Schulz RW (1997) Mismatch between patterns of circulating and testicular androgens in African catfish, Clarias gariepinus. Fish Physiol Biochem 17: 155-162.

13. Bail LPY (1996) Growth-reproduction interaction in salmonids. In: Zoha Y, Breton B (Eds.). Reproduction in Fish, Basic and Applied Aspects in Endocrinology and Genetics Les Colloques de IÕINRA, Paris 91-107.

14. Casadevall M, Bonnet S, Matallanas J (1993) Description of different stages of oogenesis in Ophiodon barbatum (Pisces, Ophidiidae). Environ Biol Fish 36:127-133.

15. Giulianini PG, Marcotullio DA, Ferrero EA (1994) Light microscopical and ultrastructural cytology of the ovaries in the sea-grass goby Zosterisessor ophiocephalus (Osteichtyes Gobiidae). Boll Zool 61:135-144.

16. Jackson LF, Sullivan CV (1995) Reproduction of white perch: The annual gametogenic cycle. Trans Am Fish Soc 124: 563-577. 
Citation:SakaBA,AdeyemoOK(2015)GonadDevelopmentintheFemaleNigerianClarias GariepinusBurchell 1822.JAquacResDevelopment6:341.doi: 10.4172/2155-9546.1000341

17. Grau A, Crespo S, Riera F, Pou S, Sarasquete MC, et al. (1996) Oogenesis in the amberjack Seriola dumerili Risso, 1810.An histological, histochemical and ultrastructural study of oocyte development. Sci Mar 60: 391-406.

18. Coward K, Bromage NR (1998) Histological classification of oocyte growth and the dynamics of ovarian recrudescence in Tilapia zillii. J of Fish Biology 53: 285-302.

19. Arocha F (2002) Oocyte development and maturity classification of swordfish from the north western Atlantic. J Fish Biol 60:13-27.

20. Richter CJJ, Eding E, Verreth JAJ, Fleuren WLG (1995) African catfish (Clarias gariepinus). In: Broodstock Management and Egg and Larval Quality (eds. N.R. Bromage and R.J. Roberts), Blackwell Science, Cambridge, pp. 242-277.
21. Anibeze CIP, Inyang NM (2000) Oocytes structure, fecundity and sex ratio of Heterobranchus longifilis (Valenciennes 1840) in Idodo River basin (Nigeria) with comments on the breeding biology. J Aquat Sci 15: 59-62.

22. Arockõaraj AJ, Haniffa MA, Seetharaman S, Singh S (2004) Cyclic changes in gonadal maturation and histological observations of threatened freshwater catfish "Narikeliru”Mystus montanus (Jerdon, 1849). Acta Ichthyologõca et Piscatoria. 34: 253-266.

23. Jalabert B (2005) Particularities of reproduction and oogenesis in teleost fish compared to mammals. Reprod Nutr Dev 45: 261- 279.

24. Olaleye VF (2005) A review of reproduction and gamete management in the African catfish (Clarias gariepinus). Ife J Sci 7: 63-70. 